\title{
Introduction to the Handbook of Social Policy and Development
}

\section{James Midgley, Rebecca Surender and Laura Alfers}

While the study of social policy in the developing world goes back many decades it is nevertheless the case that extensive and sustained attention to the subject has been largely a twenty-first-century phenomenon. To a large degree this renewed focus has been driven by fast-changing developments on the ground; specifically that we now see in many low income and emerging economies the formation of a new "world of welfare' with unique and often very large social assistance programmes, services, budgets and huge coverage. To take just one illustration, the largest social safety assistance programmes in the world are now provided by China, India and Brazil and cover almost 500 million people (a figure equivalent to the European population), and social pensions, child benefits and other cash transfers are now customary in many if not most low and middle income countries. The importance of universal health care for instrumental and ethical reasons, or social protection for mitigating the consequences of an increasingly globalized and 'disrupted' world, is now embedded in the work of the international aid and donor agencies. Consequently, there is fresh interest in evaluating the outcomes and impact of these reforms and understanding the political factors driving this new welfare expansion in the developing world. Within social policy and political science there is growing debate about the extent to which the 'old' theories of the development of the welfare state, or contemporary theories of new social risk, can explain this case of welfare expansion. Similarly, although originally focused on economic growth and industrialization, development studies is now routinely engaged with issues of social welfare and poverty reduction. While the analytic determinants and drivers of current trends may remain disputed, recognition of the importance of social policy and welfare in the developing world has indisputably gathered momentum.

It is within this context that the Handbook of Social Policy and Development is located. It utilizes the different analytic models, theories and concepts which have developed within the two interdisciplinary fields of social policy and development studies to provide an up-to-date, 
comprehensive and critical introduction to some of the key issues and debates in the study and provision of human welfare in low and middle income countries. Between them, the chapters provide an analysis of the challenges and opportunities facing welfare and social policy systems in the Global South, and examine the current strategies for addressing these challenges. The various motivations, actors, instruments and innovations involved in the provision of social welfare are outlined, and the implications of current social policy dynamics for the future of welfare outcomes in those regions are examined.

The book seeks to make these dynamics and practicalities accessible to a broad and multidisciplinary readership. Moving beyond a narrow conceptualization of food or cash, the volume adopts a broad definition of social policy which includes a range of public, private and informal mechanisms that provide income support, assets or services to vulnerable or marginalized communities. As illustrated within and across the various chapters, a variety of local, national and international actors and institutions are involved and normative debates about goals and practical debates about methods surround every sector and initiative. Moreover, the book adopts a comparative approach and illustrates the various issues, programmes and services with reference to a range of different countries and policy sectors.

In particular, the Handbook makes an explicit case for enhancing greater collaboration and integration between the two interdisciplinary fields of 'policy' and 'development' in order to arrive at a more incisive and comprehensive analysis of welfare arrangements in the developing world. Although both are committed to the goal of better understanding and promoting human welfare in the Global South, there has been little relationship between scholars and each field has adopted distinctive conceptual frameworks, research agendas and approaches to policy and practice. However, as evidenced here in the various chapter topics and multidisciplinary backgrounds of the contributors, there is clearly a case for closer collaboration between social policy and development studies. Harnessing the extensive research undertaken and insights in both fields allows for an analysis of welfare processes and institutions that is more broad ranging and overcomes the conceptual and methodological limitations of each when seeking to understand the diversity and complexity of the developing world's welfare needs and dynamics.

Equally, this volume questions the recent discourse found in both comparative social policy and development economics, that classic (that is, Western) explanatory theories for analysing welfare processes and outcomes are less relevant for the study of the developing world. It is commonly asserted that differences across the actors, structures and 
procedures that comprise systems of governance, as well as the historic legacy and economic conditions that frame them, means that traditional frameworks of comparative welfare policy in 'advanced' economies are not applicable to the transitioning economies of the South. However, as illustrated here, the past decade has witnessed a fast pace of change and a progressively integrated world in terms of policy developments. In this context, compartmentalization of welfare theory and practice in Western countries from those in the Global South, increasingly makes little sense. Whether analysing the policy mix provided by social institutions such as families, communities, civil society, employers, firms and government defining the scope of the 'needs' addressed or the coverage of the population - or evaluating the mode of delivery and financing, or the level or quality of provision aspired to, the chapters in this collection suggest that the variance between Global North and South is becoming smaller and less significant than is often assumed. This means that not only are traditional conceptual frameworks relevant for understanding events and dynamics in the South, but also, in turn, these analytic frameworks are strengthened and enhanced.

\section{SCOPE AND STRUCTURE OF THE HANDBOOK}

The Handbook is divided into three parts, concerned with social policy and development and the major social policy and welfare sectors and interventions in a development context. Part I, 'Social Policy and Development: Origins and Progression', provides a theoretical and historical introduction to the book, tracing the evolution of social policy and development studies as academic and practice fields, and providing theoretical insights into key concepts and frameworks such as welfare and development.

In Chapter 1, James Midgley argues that despite divergent histories and pathways (and ongoing belief among some that they have little in common) social policy and development studies have much to offer each other and much to gain from greater collaboration. The first half of his introductory chapter provides a detailed historical overview of the emergence of both interdisciplinary fields after the Second World War and contrasts their evolution and current characteristics. Historically concerned with Western 'welfare states', established social services and other national-level statutory intervention, Midgley argues that theoretical analysis within social policy has become more sophisticated and comparative inquiry has been broadened rapidly to include non-Western and industrialized countries, though it continues to employ a predominantly 
macro-statist approach to study the policies of these countries. The chapter proceeds to review the establishment and progress of development studies in the post-war period, again arguing that as economists, political scientists and sociologists became involved in the field, a broader theoretical interest in the factors that promote rapid economic growth and the well-being of the population (issues of poverty and inequality, education and health care, among others), emerged. The rest of the chapter traces the history of scholarly work about social welfare in the Global South to reiterate the call for closer collaboration between the two fields of study. Examples include the extensive research undertaken into social security in social policy, and social development's long engagement with non-formal welfare institutions, co-operatives and social movements, and their role in promoting social welfare. Midgley concludes by arguing that this research paves the way for closer collaboration between the two subjects and may ultimately result in the synthesis of their work.

In Chapter 2, Rebecca Surender argues that the past two decades have witnessed a rising interest in the significance of social policy in the management of welfare and risk in the developing world and a growing recognition that social development and economic development are not mutually exclusive but mutually reinforcing. However, she suggests that despite the emerging consensus about the importance of social protection itself there has been no corresponding agreement about the utility of social policy as an academic field for developing contexts. In particular, the extent to which the analytic models and concepts for the study of social policy, established in the industrialized West and North, are transportable to a developing country context, remains disputed.

The chapter traces some of the main stages in the shifting global discourse about the desirability and feasibility of social policy in low income countries and examines the extent to which the actors, institutions and ideas involved in shaping social policy in the Global South vary systematically in role and relative importance from those in the North. The discussion focuses on three current issues - the emergence of new philanthropic donors, the expansion of the developmental state model, and the surfacing of the notion of social rights and social citizenship and suggests that there is evidence of both continued divergences but also new convergence across the actors, institutions and ideas involved in shaping social policy in both hemispheres. However, the chapter concludes by cautioning that rising heterogeneity within the developing world together with the fluid and dynamic pace of change mitigates against predictable models or typologies of 'Third World' social policy 
paradigms or a linear trajectory or 'catch-up logic' with the West in terms social policy advancement.

Part II of the Handbook, 'Key Issues and Debates', is concerned with a number of topics related to the fields of social policy and development. These chapters show that very often both fields have engaged with issues such as poverty, gender and human rights, but from different perspectives. Discussing these issues, these chapters argue for a sharing of ideas and integration of conceptual approaches. Some chapters discuss issues that are largely distinctive to each field or, as in the case of the informal economy, are only starting to become a serious topic of investigation for both fields. The need to exchange knowledge in these and other fields is explored.

In Chapter 3, Laura Alfers considers the role of social movements in initiating, engaging with, challenging and resisting social change from below. She reviews the different ways that both social policy scholarship and development theory have positioned social movements. Alfers argues that while the social movement and post-development literature does much to stress the difference of the development context from that in which the study of social policy originally developed, the social policy literature adds a much-needed focus on the material gains that have been made by social movements.

Chapter 4 by Leila Patel provides an overview of changing frameworks for understanding gender and development, from women in development (WID) through to gender and development (GAD) and into the current Agenda 2030 Sustainable Development Goals (SDGs) era. The chapter highlights the key tension that exists between addressing women's material, everyday needs and challenging structural imbalances in gender relations. Patel illustrates this tension through an examination of cash transfers which have risen to prominence at the intersections of social policy and development, arguing that whilst these have demonstrated their ability to address women's poverty, questions still remain about their capacity to effect a more structural transformation in gender relations.

Following this, in Chapter 5, Huck-ju Kwon examines global social policy and its relationship to development, providing a conceptual overview of the field which provides answers to questions such as what constitutes global social policy, what differentiates it from national social policy, and how it is made and implemented at international and national levels. Kwon then moves onto a more grounded discussion of the development of global social policy instruments in the post-Second World War period, up to and including the United Nations SDGs. Ultimately, he argues, it is the integration of global social policy frameworks into national 
legislation and policy which has proven critical to the path of national development.

In Chapter 6, Marian Urbina-Ferretjans picks up on the theme of the SDGs within the context of the 2030 global social development agenda. Drawing on both development and social policy literatures - and arguing that is necessary to work through both if shifts in global development are to become visible - she compares the SDGs with its forerunner, the Millennium Development Goals (MDGs). The chapter argues that it is possible to discern a shift from the pro-poor perspective of the MDGs to a social development perspective within the SDGs, incorporating a greater focus on productivist and economic rationales for social policy provision, whilst maintaining an emphasis on universalism. UrbinaFerretjans links this shifts to the greater participation from countries of the Global South (such as the BRICS group of countries - Brazil, Russia, India, China and South Africa), not only in development policy processes, but also as providers of development assistance.

In Chapter 7, Hartley Dean discusses the subject of social and human rights, providing an overview of the emergence and construction of different rights traditions. He points out that the engagement between rights-based approaches - which originally developed in the Global North - and social development approaches from the Global South have resulted in a greater focus on human rights within a social policy discipline that has traditionally focused on social rights. Dean goes on to show that, within social development, there are competing interpretations of the role that rights can play, arguing that it is essential for social policy to critically engage with these different interpretations if the two areas of study are to find a greater synthesis with one another.

Chapters 8 and 9 focus on urbanization and rural development, respectively. In Chapter 8, Jo Beall brings attention to the challenges posed by rapid urbanization to a development framework which has traditionally oriented itself around rural contexts. Her chapter explores two areas of social policy which are most closely linked with urban development agendas - access to shelter and basic services, and livelihood opportunities - providing an analysis of the challenges city governments face in addressing these issues, located as they are between local communities and national governments. The chapter highlights a shift, encapsulated within the New Urban Agenda, away from urban development solutions which revolve around individual or community-based action, to one which focuses on city governments as agents of development and policy implementation. This highlights the need for social policy, which has often focused more strongly on the national level of 
government, to consider more fully the role of the municipal governments in policy changes and implementation.

Despite increasing urbanization, more than half the world's population still live in rural areas, albeit in a context of increasingly complex interactions with cities. In Chapter 9, Amrita Datta turns attention back to rural development and analyses the different ways in which the social policy and development literatures have characterized the subject. Tracing these differences through a range of theoretical perspectives from modernization theory through to participatory development - she shows that while social policy perspectives have emphasized rural development as a state policy, the development literature has focused more on the role of non-state actors in processes of change in rural societies. Datta argues that there has been increasing convergence between the two areas of research, although differences remain which call for greater interaction between the two fields.

The environment is the subject of Chapter 10, where Karl Falkenberg interrogates the supposed trade-off between environmental protection policies and social development. He provides a historical overview of various multilateral processes which have attempted to grapple with the balance between environmental sustainability and development. Falkenberg discusses the debates that have existed within these processes between countries of the Global North and South, with Southern countries often arguing that poverty reduction should have priority over environmental protection. This vision, he argues, has tended to ignore the needs of many indigenous communities whose existence has depended on natural resources, and which demonstrate that development and sustainability need not be seen in opposition to one another. Emphasizing the importance of national policy and regulation in undermining this binary choice, Falkenberg incorporates an analysis of policies adopted by China and South Korea to illustrate this argument.

In Chapter 11, Dina Kiwan discusses security and development, tracing the ways in which these two areas of policy and practice have come to intersect with one another through global social policy. A key shift since the end of the Cold War has been away from a state-centric conception of security, to a more individualized conception of human security which has been institutionalized in the work of international development actors such as the United Nations Development Programme (UNDP). Grounding her arguments in a case study of Syrian women refugees, Kiwan goes on to demonstrate the contested nature of the human security paradigm, contributing a gendered critique centred on the experiences of migrant women. She argues that the study of security and development would 
benefit from more contextualized engagements which draw on multiple theoretical perspectives.

In Chapter 12, Nicola Yeates examines ongoing sub-global, transnational processes at the regional level as they relate to both social policy and development. While great attention has been paid by the academic community to the European Union, Yeates points out that regional bodies have become important outside of the industrialized context, as countries increasingly seek cooperation with their neighbours to address crossborder social, economic and environmental concerns. Despite this, the significance of regional bodies in shaping and (reshaping) the governance of welfare capitalism across the globe continues to be heavily contested. Yeates provides an overview of some of the key questions and debates that have characterized the field, suggesting that there remains significant scope to further develop our understanding of the role of worldregionalism from both social policy and development perspectives.

The last two chapters of Part II focus on different aspects of the labour market as an entry point into social policy and development debates. In Chapter 13, Francie Lund concentrates on the question of informal employment, arguing that neither development studies nor social policy has engaged comprehensively enough with this issue. Definitions and statistics on informal employment have improved significantly in recent years, and Lund provides an overview of their evolution. She then suggests three critical issues of relevance to both social policy and development: the importance of local government in determining the working conditions of urban informal workers, the links between women's unpaid care work and incomes in the informal economy, and the importance of greater representation and voice of organizations of informal workers in policy processes.

In Chapter 14, Michael Rogan and Laura Alfers focus on the ways in which changing employment relationships, and particularly the erosion of the standard employment relationship, across the globe has impacted on the long-standing debate about the suitability of employment-linked social protection in development contexts. They argue that the situation is more complex than is commonly assumed, and that rather than posing the question simply as one of linking versus delinking social protection from employment, the question is better framed as one which asks under what conditions different groups of workers can gain access to various types of social protection.

The chapters in Part III of the Handbook, 'Services, Programmes and Policy Sectors', offer accounts of the major welfare policies and programmes that social policy and development studies scholars have examined. Most of this research has focused on the traditional social 
services such as health, education, housing, social protection and social work and family social services, but topics such as community development, financial inclusion and the role of voluntary organizations have also been addressed. Although these topics have been analysed from different perspectives, the chapters reveal that there is considerable overlap and scope for integrating these perspectives to provide a more comprehensive analysis. The chapters summarize this research and pay particular attention to the role of social welfare in development. They challenge the view that the social services detract from economic growth, and contend that social welfare policies and programmes function as social investments which are compatible with wider development goals. They also foster social well-being and promote social justice.

Chapter 15 by Amrit Virk provides an overview of policies and programmes for promoting health in the context of development. Focusing on low and middle income countries, she examines the way health care systems are structured and reviews key debates about how health care can be promoted so that all of the world's people can live healthy and productive lives. Universalizing health care is a major focus of health policy today, as is ensuring that access and outcomes are equalized. Noting that much progress has been made in formulating appropriate policies that challenge the colonial legacy, she recognizes that much more needs to be done to ensure equitable access and universal coverage. Achieving these goals will not only contribute positively to development but also achieve the ideal of health as a human right.

Chapter 16 by Mayumi Terano asks how education is conceptualized in social policy and development studies and how key issues and debates are presented in each field. Although there is a common concern with achieving universal access, curricular appropriateness and the quality of teaching and educational services, different perspectives have also emerged creating a need for scholars in both fields to cooperate and integrate their knowledge. Accordingly, the author advocates for a multidimensional and inclusive perspective on education which addresses the role of states, governance, rights and the role of social and political factors in educational policy. She pays attention to international initiatives that are promoting greater commonalities in educational policy, and argues for a more effective commitment to combine the goals of equity and development.

In Chapter 17, James Lee discusses the role of housing in social policy and development studies, pointing out that while there is agreement that housing needs to be compatible with both development and social welfare, the policies formulated by governments and voluntary organizations have not succeeded in achieving this goal. A major reason for 
this failure is the fundamental shift which has taken place in housing policy, favouring market allocation and privatization. To resolve the issue, the importance of housing as an asset and wealth-building instrument needs to be recognized. Using John Rawls's concept of a propertyowning democracy, the chapter concludes by suggesting that a policy of home ownership promoted by the state could provide a sustainable and socially just model of housing policy for both Western and developing nations.

The following two chapters by James Midgley discuss the historical evolution and key features of social insurance and social protection, and consider their role in development. Chapter 18 pays special attention to social insurance pensions, which are widely used to meet the income needs of retired workers in Western countries and increasingly in the developing countries where populations are ageing. It reviews some of the challenges facing social insurance such as coverage, equity, administrative effectiveness and cost, and considers future directions for social insurance. Contrary to the claims of market liberal critics who advocate the privatization of social insurance, the author argues that the challenges facing these schemes can be resolved without abandoning their basic principles. With appropriate modifications, social insurance can make a positive contribution to development and promote social justice for the world's people.

Next, in Chapter 19, Midgley provides an overview of social assistance and examines its role in development. Although previously limited in scope, social assistance is being used widely today to alleviate global poverty. The author traces the evolution of social assistance from its formative association with charitable almsgiving to its current role in reducing poverty and deprivation. He provides an overview of the key features of social assistance, noting that the use of the means test and other conditionalities are common features of these schemes. In addition to paying cash benefits, food subsidies and supplements are widely used. Unique forms of social assistance such as conditional income transfers, community works projects and local nutritional programmes targeted at women and children are discussed. Although social assistance is hampered by implementation, funding and other difficulties, the chapter shows that it is helping to meet the poverty reduction targets of the Sustainable Development Goals.

In Chapter 20, Armando Barrientos provides an overview of conditional income transfers, showing that their rationale lies in an understanding of poverty as caused by deficits in productive capacity. They are conditional on children attending school and on household members attending primary health care, especially expectant mothers and infants. 
The author contends that their core design feature, namely the combination of income transfers with incentives for human development, is an effective intervention. Extensive research, including impact evaluations into the outcomes of conditional income transfers, confirms that they are broadly meeting their objectives, with variation across countries and programmes. This research also reveals that they are strong and innovative welfare institutions, especially in middle income countries, and that eradicating poverty requires improving the productive capacity of low income groups, and children in particular.

Chapter 21 by Antoinette Lombard provides an overview of social work and family services and considers their implications for development. The author traces the historical evolution of social work and family welfare services, discussing how since ancient times non-formal welfare gradually gave way to formalized social welfare through faith-based organizations, government intervention and professional social work. Different social work interventions for families are outlined, emphasizing the relevance of empowerment and strength-based approaches. Family services are outlined from both a micro and a macro practice perspective, indicating that both are important if social work is to achieve social justice for all people. The author also discusses how social work can contribute to social development within a global sustainable development framework, and concludes that effective social work requires the integrated non-formal and formal welfare framework, based on government policies that strengthen the involvement of families and communities in caring for their members.

In Chapter 22, Philip Mader and Solène Morvant-Roux ask whether access to financial services constitutes an urgent universal human need, and they probe for empirical evidence regarding the potential benefits and harms of financial inclusion. The authors discuss different approaches to understanding and defining financial inclusion, and then look at the history of microfinance. They examine the empirical evidence for and against poverty alleviation and women's empowerment resulting from financial inclusion, which they believe is inconclusive. Discussing the broader politics of financial inclusion, the authors highlight how it is implicated in a broader financialization of development, which inserts market logics into non-market spaces and enables new forms of accumulation, without necessarily contributing to development. They conclude that the value of financial inclusion, as an intervention governed by the unequal rules and power relations of financial systems, remains questionable.

Next, in Chapter 23, Manohar Pawar observes that community development programmes play a crucial role in both social policy and 
development. The author discusses the meaning of community development in historical and contemporary contexts, and outlines the basic strategies used in community development practice. He shows how these programmes are implemented to facilitate social, economic and political development of people and their communities in both Western and developing countries. He summarizes the main strengths and weaknesses of community development programmes, noting that implementing these programmes according to the values and principles of social justice is yet to be achieved. However, he concludes that there is a great potential to achieve these ideals through improvement and reforms.

In the final chapter of Part III, Roosa Jolkkonen contends that non-governmental organizations (NGOs) are central actors in implementing social welfare and development policies. Beside their welfare function, they are recognized as prominent policy advocates, furthering social transformation by shaping development and social policy agendas. They are a fundamental building block of the welfare mix (also known as the division of welfare) between the state, market, family and the non-profit or 'third' sector. Despite the similar roles NGOs play in both Western countries and the Global South, the academic study of these organizations has taken divergent paths: NGOs operating in the Global South have been mainly studied by scholars in development studies as 'development organizations', while those operating in the Global North have been investigated by social policy scholars as 'charities' and 'nonprofits'. Questioning this separation, the author highlights their similarities and argues for the integration of these two perspectives so that NGOs can more effectively promote social welfare, development and social justice around the world. 